\title{
CREATIVE GENERATION
}

\section{Introduction to Case-making and Systems Change in Arts \& Cultural Education}

\section{Laurie T. Schell ${ }^{*}$ \\ Creative Generation; Nashville, TN, USA}

\section{abstract:}

Introduction to Case-making and Systems Change in Arts \& Cultural Education is an overview of a collaborative project between Creative Generation and ElevateArtsEd undertaken to better understand how practitioners - such as artists, educators, community leaders, and more - can make the case for and also advocate through arts and culture to drive systemic change and address complex challenges. The project seeks to expand the knowledge base of case-making and systems change in the field of arts and cultural education and provide resources to support effective actions for practitioners and young creatives. Investigating both the theory and the practice of case-making, the introductory article draws on research from three distinct sectors: cultural, education, and social justice. The approach represents both the science of advocacy-- building blocks for understanding what effective advocacy looks like- and the art of advocacy with calls for improvisation, adaptability, and generative thinking, all characteristics of art making. The article describes six key learning themes and an expanded model for advocacy focused and self, field, and sector through an overarching lens of social justice

\section{keywords:}

arts and culture, systems change, case-making, advocacy, social justice, arts education, music education

\section{suggested citation:}

Schell, Laurie T. (2022) Introduction to case-making and systems change in arts \& cultural education, Creative Generation Journal, 3:1, 1-6, DOI: 10.51163/creative-gen009

*Laurie T. Schell is founder of Elevate Arts Ed and a Sr. Specialist, Content \& Training with Creative Generation; laurie@elevateartsed.org 
As part of our commitment to authentically engaged learning, this article has been formatted to encourage critical dialogue with the text. Throughout, there are numerous spaces to write, draw, or otherwise reflect while reading the text.

\section{Introduction}

I am a lifetime advocate for arts education. In more recent years especially since 2020 - as the whole world shifted, I witnessed the arts serving as a vehicle for society to grapple with these changes. So, my perspective has grown. I am an advocate for arts and cultural education and its powerful impacts on the development of young people, and I see how it can be the means for our systems, policies, and communities can grow and positively change towards a more just future.

In 2021, a collaborative project between Creative Generation and ElevateArtsEd emerged to better understand how practitioners - such as artists, educators, community leaders, and more - can make the case for and also advocate through arts and culture to drive systemic change and address the complex challenges we were facing, such as a global health pandemic, reckoning with racial justice, environmental crisis, threats to public education, and economic recession. The goal of the project was to expand the knowledge base of case-making and systems change in the field of arts and cultural education and provide resources to support effective actions for these practitioners (and young creatives, too!). What has resulted is a suite of essays investigating the theory and practice of case-making and systems change for and through arts and cultural education.

The work is grounded in research with an annotated bibliography and overview of current literature from three distinct sectors: culture, education, and social justice. The selected studies represent both the science of advocacy - building blocks for understanding what effective advocacy looks like - and the art of advocacy with calls for improvisation, adaptability, and generative thinking, all characteristics of art making. 


\section{Expanding on a New Model}

The suite of articles is grouped within three categories, as identified in Jeff $M$. Poulin's essay "Embedding Advocacy Into Your Practice" published by the Teaching Artists Guild:

- advocacy for self;

- advocacy for the field; and

- advocacy for the sector

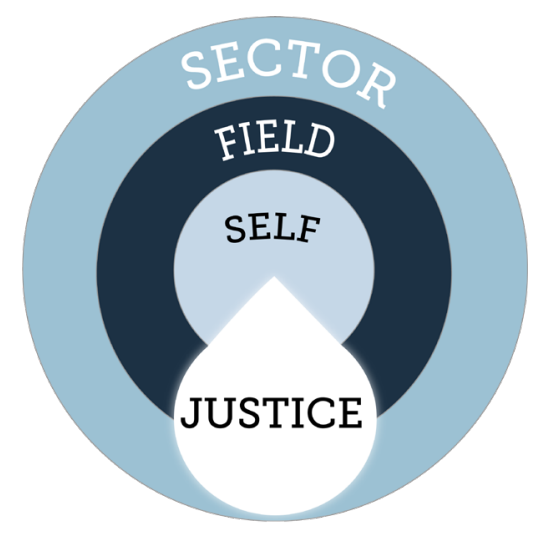

Overarching is the concept of 'advocacy for justice,' recognizing that advancing social justice is embedded in all efforts within the self, field, sector, or broader community. As Poulin states:

"We cannot realize the work, field, or sector we envision without a justice orientation. If our Black, Indigenous, and peers of color are not treated equitably, if our communities on the margins are not supported, and if young people are not centered in the work, the field ... cannot be fully realized.
"At all levels of our advocacy - for self, field, and sector - we must seek justice. Within this process, we can and must take steps to examine our own privilege and use our power to create pathways to achieving justice" (Poulin, 2021.).

Advocacy for Self includes articles on individual responsibility and the need to experience the work from multiple perspectives.

\section{Advocacy for the Field explores} structural elements of advocacy efforts and the importance of strategic communications, issues that may be relevant to fields within the larger landscape (e.g., educators, teaching artists, administrators).

Advocacy for the Sector explores systems change through arts education and stakeholder participation and engagement strategies.

Making the Case for Justice looks at pathways to consider in the work to realize principles of social justice in the arts. 


\section{Key Learning Themes}

The articles are based on one or more key learning themes gleaned from a review of the extant literature on advocacy, case-making, and systems change in the arts, health, housing, social justice, environment, and economic sectors. Each are based around the necessary action of a practitioner within their own context:

- See the larger system and work within a local context

- Balance organizational structure and flexibility

- Link communications strategies to goals

- Build adaptive processes that encourage engagement

- Understand the dynamics of systems change

- Acknowledge progress at all levels

These actions can be individually practiced and improved, and when taken together drive the systemic change we wish to see.

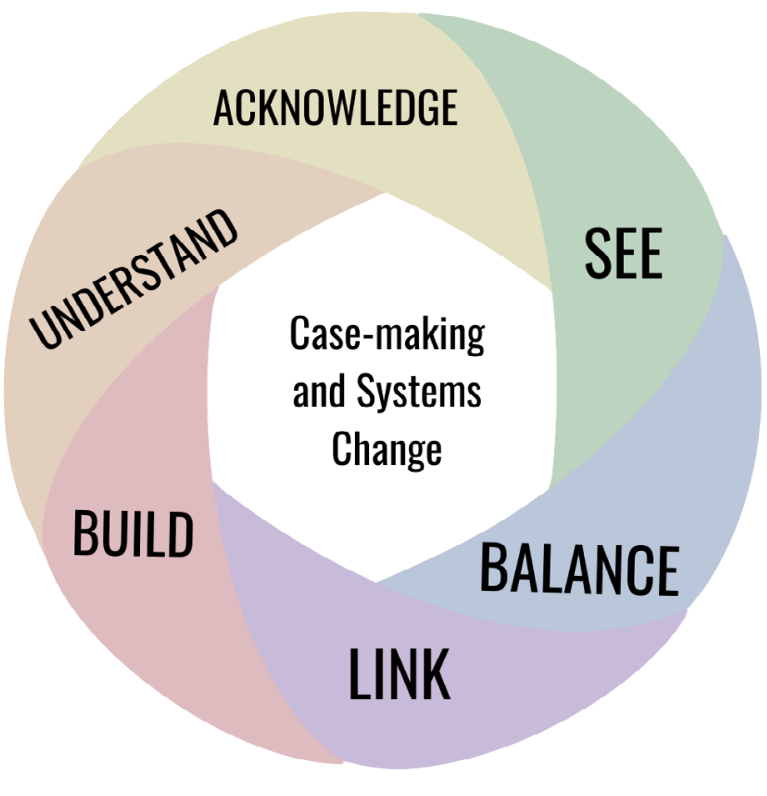

Case-making and systems change are multifaceted. As with the artistic process, so, too, the process of advocacy engagement is as important as the final product of outcomes. This suite of articles will demonstrate the dynamic and iterative nature of advocacy work. There is no one right answer; there is only one right answer for right now. There is no immediate solution; the process is a long game, often taking years to reach a conclusion.

Author's note: Making the Case does not include research studies on the value or benefits of the arts and arts education. If you are looking for research to bolster your case, there are significant resources, found at the end of this article. 


\section{References}

Poulin, Jeff. "Embedding advocacy into your practice." Teaching Artist Guild.

Accessed Aug. 5, 2021. https://teachingartists.com/quarterly_magazine/embeddingadvocacy-into-your-practice/

\section{Resources:}

https://www.artsedsearch.org/

https://www.nammfoundation.org/WHY-MUSIC-MATTERS\%20 
Laurie T. Schell

Senior Specialist, Content \& Training Creative Generation; Nashville, TN

Laurie Schell (she/her) serves as the Senior Specialist for Content and Training with a focus on case making and systems change. In this role, she contributes to specific projects related to professional development and curriculum development.

Laurie is founding principal of Laurie Schell Associates | ElevateArtsEd, providing consulting services and issue expertise in arts education. Widely recognized for leadership in the nonprofit and education sectors, Laurie Schell has worked to foster arts education through strategic alliances and partnerships, policy and advocacy campaigns, innovative programs, directed research, and mobilizing constituencies for action.

Ms. Schell served as the the inaugural director of Music Makes Us (20122017), the public/private music education initiative in Metro Nashville Public Schools, jointly supported by the mayor's office, music industry, and the school district. During her tenure, participation in music increased to over $60 \%$ of the $\mathrm{K}-12$ student population. Forty-five classes were added in 18 schools, with over $\$ 5$ million raised in private and government funds to augment district funding.

Previously, Ms. Schell was the executive director of the California Alliance for Arts Education (2001 - 2011), where she led a successful campaign to secure a historic $\$ 605$ million investment in $\mathrm{K}-12$ arts education, co-edited numerous policy papers, and co-created the Insider's Guide to Arts Education Planning, now in its 3rd edition.

Ms. Schell holds a B.A. from Stanford University, an M.A. in Liberal Studies/ Dance from Wesleyan University in Connecticut and pursued further studies at the Harvard Kennedy School of Government. She currently serves on the board of Save the Music Foundation and ArtsEd Tennessee, a statewide advocacy coalition.

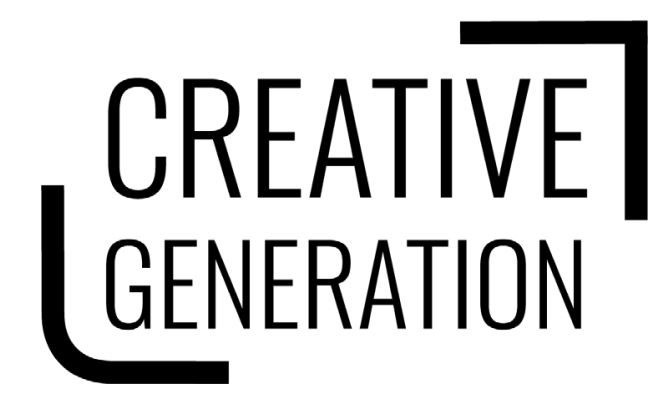

Creative Generation collaborates with young creatives and those who cultivate their creativity to take local actions towards global changes in pursuit of a more just world. Learn more at wWw.Creative-Generation.org 